\title{
Chlorosphaerolactylates A-D: Natural Lactylates of Chlorinated Fatty Acids Isolated from the Cyanobacterium Sphaerospermopsis sp. LEGE 00249
}

Ignacio Gutiérrez-del-Río, Nelly Brugerolle de Fraissinette, " Raquel Castelo-Branco," Flavio Oliveira, João Morais, Saúl Redondo-Blanco, Claudio J. Villar, María José Iglesias, Raquel Soengas, Virginio Cepas, Yuly López Cubillos, Giacomo Sampietro, Liliana Rodolfi, Felipe Lombó, Sara M. Soto González, Fernando López Ortiz,* Vitor Vasconcelos, and Mariana A. Reis*

Cite This: J. Nat. Prod. 2020, 83, 1885-1890

Read Online

ACCESS I L IIll Metrics \& More | 国 Article Recommendations

Supporting Information

ABSTRACT: Four natural lactylates of chlorinated fatty acids, chlorosphaerolactylates A-D (1-4), were isolated from the methanolic extract of the cyanobacterium Sphaerospermopsis sp. LEGE 00249 through a combination of bioassay-guided and MSguided approaches. Compounds 1-4 are esters of (mono-, di-, or tri)chlorinated lauric acid and lactic acid, whose structures were assigned on the basis of spectrometric and spectroscopic methods inclusive of $1 \mathrm{D}$ and 2D NMR experiments. High-resolution massspectrometry data sets also demonstrated the existence of other minor components that were identified as chlorosphaero(bis)lactylate analogues. The chlorosphaerolactylates were tested for potential antibacterial, antifungal, and antibiofilm properties using

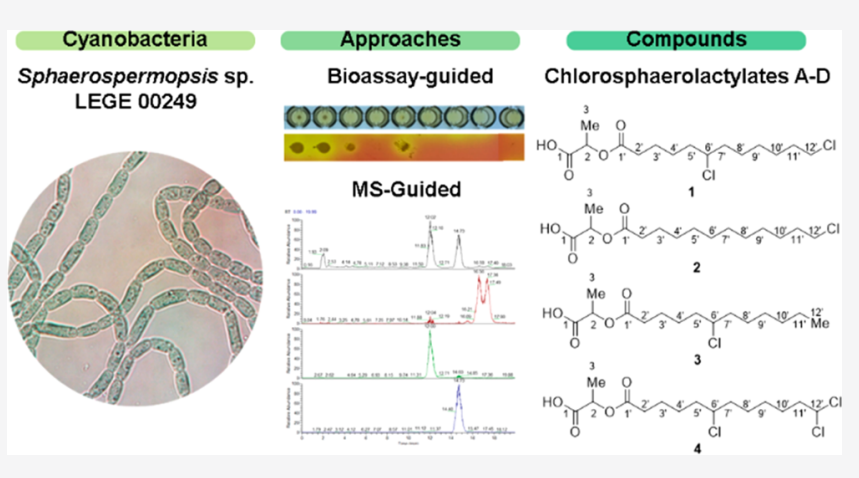
bacterial and fungal clinical isolates. Compounds 1-4 showed a weak inhibitory effect on the growth of Staphylococcus aureus S54F9 and Candida parapsilosis SMI416, as well as on the biofilm formation of coagulase-negative Staphylococcus hominis FI31.

$\mathrm{O}$ ver the past few decades, cyanobacteria have been considered as one of the most promising groups of bacteria for natural products discovery. ${ }^{1,2}$ Owing to the distinct ecological niches that these organisms occupy and their particular ecophysiology, natural products synthesized by cyanobacteria are diverse and structurally unique. ${ }^{3}$ These metabolites can be peptides, polyketides, derivatives of fatty acids, and hybrids thereof, many featuring unusual modifications such as halogenation. ${ }^{4}$ More than 5000 halogenated compounds have been isolated from natural sources including bacteria, fungi, algae, higher plants, invertebrates, and vertebrates from distinct environments. ${ }^{5,6}$ Furthermore, the presence of halogen substituents (such as chlorine, bromine, and more rarely iodine and fluorine) in natural products influences their biological activity, ${ }^{7}$ representing a valuable and expanding class of natural products. In the past years, several halogenated fatty acids amide derivatives were isolated from marine cyanobacteria including the malyngamides, ${ }^{8}$ the jamaicamides, ${ }^{9}$ the grenadamides, ${ }^{10}$ and the columbamides. ${ }^{11}$ These compounds have been associated with biological activities such as cytotoxicity, calcium and sodium channel modulation, and cannabinoid receptor binding. Additional examples of halogenated fatty acids incorporated in natural peptides can be found in the literature, such as the puwainaphycins originating from a terrestrial cyanobacterium ${ }^{12}$ or lyngbyabellin extracted from the marine cyanobacterium Lyngbya majuscula. ${ }^{13}$ Moreover, an unusual and fascinating class of chlorosulfolipids was reported in a Nostoc sp. strain, ${ }^{14}$ and more recently aranazoles, extensively polychlorinated compounds were described in a Fischerella sp. strain, ${ }^{15}$ proving once again the wide structural diversity of halogenated metabolites that cyanobacteria are capable of producing.

Our current interest in identifying new cyanobacterial metabolites with antibiotic and antibiofilm activity in the framework of the NoMorFilm project ${ }^{16}$ led us to investigate the chemical diversity of cyanobacterial strains from the Blue Biotechnology and Ecotoxicology Culture Collection, LEGECC (based at CIIMAR). Through a bioassay-guided approach, Sphaerospermopsis sp. LEGE 00249 was pinpointed as a promising producer of antibiofilm and antibacterial metabolites. This cyanobacterial strain was isolated from a Portuguese

Received: January 20, 2020

Published: June 1, 2020 


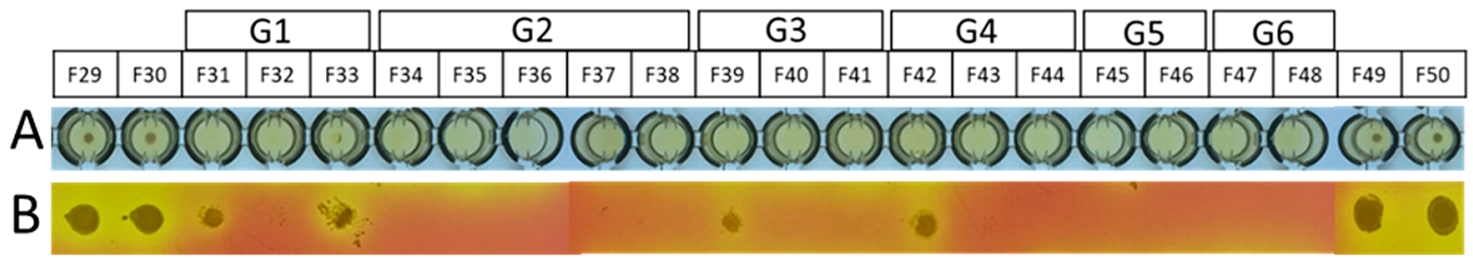

Figure 1. Bioassay-guided discovery of antibacterial compounds. Schematic representation of a 96-well plate containing active fractions: (A) microbial sediments obtained after the microdilution antibiotic susceptibility test; (B) result of the bactericidal assay after the upper wells were subcultured onto a solid agar medium (MSA). Inhibition of S. aureus S54F9 growth was observed in fractions F32, F34-38, F40, F41, F43-F48. The groups G1-G6 were defined according to their chemical composition after HRESIMS analyses.

\section{Chart 1}

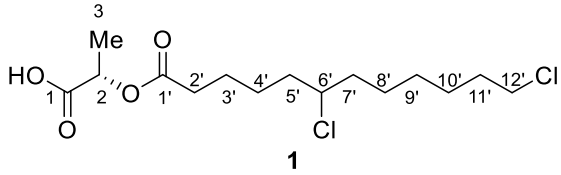<smiles>CCCCCCC(Cl)CCCCCC(=O)OC(C)C(=O)O</smiles>

3<smiles>CC(OC(=O)CCCCCCCCCC=CCCl)C(=O)O</smiles><smiles>CC(OC(=O)CCCCC(Cl)CCCCC=C(Cl)Cl)C(=O)O</smiles>

Table 1. ${ }^{1} \mathrm{H}$ NMR (600.13 MHz) and ${ }^{13} \mathrm{C}$ NMR (150.9 MHz) Spectroscopic Data $(\delta$ in ppm) for Compounds $1-4$

\begin{tabular}{|c|c|c|c|c|c|c|c|c|}
\hline \multirow[b]{2}{*}{ position } & \multicolumn{2}{|c|}{ chlorosphaerolactylate A (1) } & \multicolumn{2}{|c|}{ chlorosphaerolactylate B (2) } & \multicolumn{2}{|c|}{ chlorosphaerolactylate C (3) } & \multicolumn{2}{|c|}{ chlorosphaerolactylate D (4) } \\
\hline & $\delta_{\mathrm{C}}$, type & $\delta_{\mathrm{H}}(J$ in $\mathrm{Hz})$ & $\delta_{\mathrm{C}}$, type & $\delta_{\mathrm{H}}(J$ in $\mathrm{Hz})$ & $\delta_{\mathrm{C}}$, type & $\delta_{\mathrm{H}}(J$ in $\mathrm{Hz})$ & $\delta_{\mathrm{C}}$, type & $\delta_{\mathrm{H}}(J$ in $\mathrm{Hz})$ \\
\hline 1 & $175.1,^{a} \mathrm{C}$ & & $176.5,{ }^{a}, \mathrm{C}$ & & $175.6,^{a} \mathrm{C}$ & & $178.7^{a} \mathrm{C}$ & \\
\hline 2 & 70.3, CH & $4.99, \mathrm{q}(7.2)$ & 71.2, CH & $4.99, \mathrm{q}(7.1)$ & 70.6, CH & $4.99, \mathrm{q}(7.1)$ & 72.7, CH & $4.91, \mathrm{q}(7.1)$ \\
\hline 3 & 17.4, $\mathrm{CH}_{3}$ & $1.46, \mathrm{~d}(7.2)$ & 17.7, $\mathrm{CH}_{3}$ & $1.44, \mathrm{~d}(7.1)$ & 17.6, $\mathrm{CH}_{3}$ & $1.45, \mathrm{~d}(7.1)$ & $18.2, \mathrm{CH}_{3}$ & $1.42, \mathrm{~d}(7.1)$ \\
\hline $1^{\prime}$ & 174.7, C & & 175.1, C & & $174.7, \mathrm{C}$ & & 175.1, C & \\
\hline $2^{\prime}$ & $34.6, \mathrm{CH}_{2}$ & $2.40, \mathrm{~m}$ & $34.9, \mathrm{CH}_{2}$ & 2.37, m & 34.7, $\mathrm{CH}_{2}$ & $2.41, \mathrm{~m}$ & 34.9, $\mathrm{CH}_{2}$ & $2.4, \mathrm{~m}$ \\
\hline $3^{\prime}$ & 25.4, $\mathrm{CH}_{2}$ & $1.65, \mathrm{~m}$ & 25.9, $\mathrm{CH}_{2}$ & $1.62, \mathrm{~m}$ & 25.4, $\mathrm{CH}_{2}$ & $\begin{array}{l}1.64, \mathrm{~m} \\
1.67, \mathrm{~m}\end{array}$ & 25.4, $\mathrm{CH}_{2}$ & $1.64, \mathrm{~m}$ \\
\hline $4^{\prime}$ & 27.0, $\mathrm{CH}_{2}$ & $\begin{array}{l}1.48, \mathrm{~m} \\
1.59, \mathrm{~m}\end{array}$ & $30.2, \mathrm{CH}_{2}$ & $1.35, \mathrm{~m}$ & 27.0, $\mathrm{CH}_{2}$ & $\begin{array}{l}1.49, \mathrm{~m} \\
1.59, \mathrm{~m}\end{array}$ & 27.1, $\mathrm{CH}_{2}$ & $\begin{array}{l}1.47, \mathrm{~m} \\
1.57, \mathrm{~m}\end{array}$ \\
\hline $\begin{array}{l}5^{\prime} \mathrm{b} \\
5^{\prime} \mathrm{a}\end{array}$ & 39.3, $\mathrm{CH}_{2}$ & $\begin{array}{l}1.69, \mathrm{~m} \\
1.77, \mathrm{~m}\end{array}$ & $30.4, \mathrm{CH}_{2}$ & $1.33, \mathrm{~m}$ & 39.3, $\mathrm{CH}_{2}$ & $\begin{array}{l}1.68, \mathrm{~m} \\
1.78, \mathrm{~m}\end{array}$ & 39.3, $\mathrm{CH}_{2}$ & $\begin{array}{l}1.69, \mathrm{~m} \\
1.78, \mathrm{~m}\end{array}$ \\
\hline $6^{\prime}$ & $64.8, \mathrm{CH}$ & $3.93, \mathrm{~m}$ & $30.5^{b} / 30.6^{b} \mathrm{CH}_{2}$ & $1.32, \mathrm{~m}$ & 64.9, $\mathrm{CH}$ & $3.92, \mathrm{~m}$ & $64.8, \mathrm{CH}$ & $3.94, \mathrm{~m}$ \\
\hline $\begin{array}{l}7^{\prime} \mathrm{b} \\
7^{\prime} \mathrm{a}\end{array}$ & $39.5, \mathrm{CH}_{2}$ & $\begin{array}{l}1.69, \mathrm{~m} \\
1.77, \mathrm{~m}\end{array}$ & & $1.32, \mathrm{~m}$ & 39.7, $\mathrm{CH}_{2}$ & $\begin{array}{l}1.66, \mathrm{~m} \\
1.76, \mathrm{~m}\end{array}$ & 39.4, $\mathrm{CH}_{2}$ & $\begin{array}{l}1.69, \mathrm{~m} \\
1.78, \mathrm{~m}\end{array}$ \\
\hline $\begin{array}{l}8^{\prime} \mathrm{b} \\
8^{\prime} \mathrm{a}\end{array}$ & 27.4, $\mathrm{CH}_{2}$ & $\begin{array}{l}1.48, \mathrm{~m} \\
1.56, \mathrm{~m}\end{array}$ & & $1.32, \mathrm{~m}$ & $30.0, \mathrm{CH}_{2}$ & $1.32, \mathrm{~m}$ & 27.3, $\mathrm{CH}_{2}$ & $\begin{array}{l}1.45, \mathrm{~m} \\
1.56, \mathrm{~m}\end{array}$ \\
\hline $\begin{array}{l}9^{\prime} \mathrm{b} \\
9^{\prime} \mathrm{a}\end{array}$ & 29.5, $\mathrm{CH}_{2}$ & $\begin{array}{l}1.35, \mathrm{~m} \\
1.37, \mathrm{~m}\end{array}$ & $30.0, \mathrm{CH}_{2}$ & $1.34, \mathrm{~m}$ & 27.5, $\mathrm{CH}_{2}$ & $\begin{array}{l}1.42, \mathrm{~m} \\
1.53, \mathrm{~m}\end{array}$ & 29.1, $\mathrm{CH}_{2}$ & $1.38, \mathrm{~m}$ \\
\hline $10^{\prime}$ & 27.8, $\mathrm{CH}_{2}$ & $1.46, \mathrm{~m}$ & 27.9, $\mathrm{CH}_{2}$ & $1.44, \mathrm{~m}$ & 32.9, $\mathrm{CH}_{2}$ & $1.30, \mathrm{~m}$ & 26.9, $\mathrm{CH}_{2}$ & $1.57, \mathrm{~m}$ \\
\hline $11^{\prime}$ & 33.7, $\mathrm{CH}_{2}$ & $1.77, \mathrm{~m}$ & $33.8, \mathrm{CH}_{2}$ & $1.75, \mathrm{~m}$ & 23.6, $\mathrm{CH}_{2}$ & $1.33, \mathrm{~m}$ & 44.7, $\mathrm{CH}_{2}$ & $2.19, \mathrm{~m}$ \\
\hline $12^{\prime}$ & 45.7, $\mathrm{CH}_{2}$ & $3.56, \mathrm{t}(6.7)$ & 45.7, $\mathrm{CH}_{2}$ & $3.55, \mathrm{t}(6.6)$ & $14.4, \mathrm{CH}_{3}$ & $0.91, \mathrm{t}(7.0)$ & 75.0, CH & $5.99, \mathrm{t}(6.1)$ \\
\hline
\end{tabular}

freshwater reservoir and was previously reported as a producer of a prenylated cyanobactin, a cyclic peptide produced by ribosomal synthesis. ${ }^{17}$ Herein, we describe the detection, isolation, structure elucidation, and bioactivity of four new lactylates of chlorinated fatty acids of cyanobacterial origin, the chlorosphaerolactylates A-D (1-4). Moreover, detection of masses corresponding to compounds of the chlorosphaerolactylate type or chlorosphaerobislactylate type is also reported.

\section{RESULTS AND DISCUSSION}

We have recently reported a preliminary screening assay for inhibition of microbial biofilm formation by cyanobacterial organic extracts. ${ }^{16}$ From the screening assay the methanolic extract of the strain Sphaerospermopsis sp. LEGE 00249 was selected as promising for isolation of active compounds (minimum bactericidal concentration; $\mathrm{MBC}<4.6 \mathrm{mg} / \mathrm{mL}$ ). This cyanobacterial strain was regrown ( $50 \mathrm{~L}$ laboratory scale), and its biomass was sequentially extracted with hexane, EtOAc, and $\mathrm{MeOH}$; the latter was submitted to bioassay-guided fractionation, assisted by HPLC, on the basis of the growth 
inhibition of the clinical isolate Staphylococcus aureus S54F9 ${ }^{18}$ (Figure S1). The MBC was calculated for some of the active fractions (Figure 1): F37 $<16.6 \mathrm{mg} / \mathrm{mL}, \mathrm{F} 40<5.2 \mathrm{mg} / \mathrm{mL}$, $\mathrm{F} 43<6.4 \mathrm{mg} / \mathrm{mL}$, and $\mathrm{F} 45<10 \mathrm{mg} / \mathrm{mL}$.

Analysis of the active fractions by HRESIMS yielded six groups (G1-G6; Figure 1) that were defined according to their chemical composition. The presence of various mass peaks showing typical chlorine isotope patterns indicated the fractions contained compounds bearing one, two, or three chlorine atoms (Figure S2). More specifically, group G2 presented the isotope pattern at $\mathrm{m} / z$ 339/341/343 (100:69.9:11 ratio), consistent with the presence of two chlorine atoms in the molecule $\left(m / z 339.1117[\mathrm{M}-\mathrm{H}]^{-}\right.$; $\mathrm{C}_{15} \mathrm{H}_{26} \mathrm{Cl}_{2} \mathrm{O}_{4}$ ), and group $\mathrm{G} 3$ showed the isotope cluster at $m$ / $z 373 / 375 / 377 / 379$ (100:92.8:30.9:3.5 ratio), indicating the molecule to bear three chlorine substituents $(\mathrm{m} / z 373.0707$ $\left.[\mathrm{M}-\mathrm{H}]^{-} ; \mathrm{C}_{15} \mathrm{H}_{25} \mathrm{Cl}_{3} \mathrm{O}_{4}\right)$. Furthermore, groups $\mathrm{G} 4$ and $\mathrm{G5}$ showed an isotope pattern at $\mathrm{m} / z$ 305/307 (100:32.7 ratio), consistent with the presence of only one chlorine atom $(\mathrm{m} / z$ $305.1504[\mathrm{M}-\mathrm{H}]^{-}$and $m / z$ 305.1509 $[\mathrm{M}-\mathrm{H}]^{-}$, respectively; $\mathrm{C}_{15} \mathrm{H}_{27} \mathrm{ClO}_{4}$ ). Although $\mathrm{G} 4$ and $\mathrm{G} 5$ showed peaks with the same mass, these presented different retention times (Figure S2), suggesting these molecules to be structural isomers. Finally, the chlorine isotopic patterns in groups G1 and G6 were of low intensity (close to the baseline), and the amounts of these compounds were not suitable for NMR experiments.

The structures of compounds $\mathbf{1 - 4}$ were elucidated through the combination of spectroscopic and spectrometric methods. They were identified as esters of chlorinated lauric acid and lactic acid. Nevertheless, the amounts isolated from the $50 \mathrm{~L}$ culture were not enough to establish an unambiguous structure for compound 4 and to evaluate the antibiofilm activity; therefore the cyanobacterial strain was regrown using Green Wall Panel (GWP-III) outdoor photobioreactors. Compounds 1-4 were then isolated from this biomass guided by MS; however suitable conditions to separate $\mathbf{2}$ and $\mathbf{3}$ were not found, so they were isolated as a mixture.

Compound 1, named chlorosphaerolactylate A, was obtained as an oil $\left([\alpha]^{24}{ }_{D}+34.1\right)$. The molecular formula $\mathrm{C}_{15} \mathrm{H}_{26} \mathrm{Cl}_{2} \mathrm{O}_{4}$, consistent with two degrees of unsaturation, was deduced from the HRESIMS spectrum showing the deprotonated molecule mass peak at $m / z 339.1117[\mathrm{M}-\mathrm{H}]^{-}$. The IR spectra showed a broad absorption band in the range 3019$2797 \mathrm{~cm}^{-1}$ (v-shaped) along with absorptions at 1736 and $1725 \mathrm{~cm}^{-1}$, suggesting the presence of two $\mathrm{O}=\mathrm{C}-\mathrm{OR}$ moieties, one of them being a carboxyl functional group ( $\mathrm{R}$ $=\mathrm{H})$. These findings were corroborated by the ${ }^{13} \mathrm{C}$ NMR signals at $\delta_{\mathrm{C}} 175.1$ (broad) and 174.7 and account for the two degrees of unsaturation. The 2D HSQC-edited spectrum showed that the remaining 13 carbon atoms consisted of one $\mathrm{CH}_{3}, 10 \mathrm{CH}_{2}$, and two $\mathrm{CH}$ (Table 1). The structure assignment was based on the analysis of the correlations observed in the 2D HMBC, HSQC-edited, and COSY NMR spectra. The methine C-2, C- $6^{\prime}$ and methylene carbons C-2', $\mathrm{C}-12^{\prime}$ were easily identified on the basis of their chemical shifts. Key connections deduced from the HMBC and COSY spectra were used to establish the connectivity along the carbon skeleton and are shown in Figure 2. Starting with the HMBC spectrum, the doublet at $\delta 1.46(J=7.2 \mathrm{~Hz})$ of the methyl group $\mathrm{H}_{3}-3$ showed three correlations with the methine carbon C-2 at $\delta_{\mathrm{C}} 70.3$ and with the two carbonyl carbons C-1/ $\mathrm{C}-1^{\prime}$ at $\delta_{\mathrm{C}} 175.1 / 174.7$. The correlation of the methylene

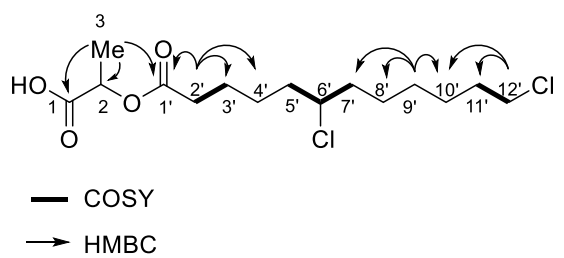

Figure 2. Key COSY and HMBC correlations of chlorosphaerolactylate A (1).

protons $\mathrm{H}-2^{\prime}$ (multiplet, $\delta_{\mathrm{H}} 2.4$ ) with the most shielded signal indicated that it belongs to $\mathrm{C}-1^{\prime}\left(\delta_{\mathrm{C}} 174.7\right)$. H-2' also correlated with $\mathrm{C}-3^{\prime}\left(\delta_{\mathrm{C}} 25.4\right)$ and C-4' $\left(\delta_{\mathrm{C}} 27.0\right)$. The distinction between the two carbons was achieved through the identification of $\mathrm{H}-3^{\prime}\left(\mathrm{m}, \delta_{\mathrm{H}} 1.65\right)$ via its COSY correlation with $\mathrm{H}-2^{\prime}$ and the subsequent HSQC correlation of $\mathrm{H}-3^{\prime}$ with the carbon atom to which it is directly bonded. The same strategy was applied to assign the three methylene groups at the other end of the molecule. The triplet at $\delta_{\mathrm{H}} 3.56(\mathrm{~J}=6.7$ $\mathrm{Hz}$ ) resulting from the protons $\mathrm{H}-12^{\prime}$ correlated with $\mathrm{C}-10^{\prime}$ $\left(\delta_{\mathrm{C}} 27.8\right)$ and $\mathrm{C}-11^{\prime}\left(\delta_{\mathrm{C}} 33.7\right)$ in the HMBC spectrum. The latter was assigned based on the $\mathrm{H}-12^{\prime}, \mathrm{H}-11^{\prime}\left(\mathrm{m}, \delta_{\mathrm{H}} 1.77\right)$ and $\mathrm{H}-11^{\prime}, \mathrm{C}-11^{\prime}$ correlations observed in the COSY and HSQC spectra, respectively. The carbons at position $\mathrm{C}-10^{\prime}$ and $\mathrm{C}-11^{\prime}$ also showed correlations with the diastereotopic protons $\mathrm{H}$ $9 \mathrm{a}^{\prime} / \mathrm{H}-9 \mathrm{~b}^{\prime}\left(\mathrm{m}, \delta_{\mathrm{H}} 1.37\right.$ and 1.35$)$, which in turn correlated with two additional carbon atoms at $\delta_{\mathrm{C}} 27.4$ and 39.5. They must correspond to $\mathrm{C}-8^{\prime}$ and $\mathrm{C}-7^{\prime}$, respectively. This assignment was supported by the COSY correlations of $\mathrm{H}-6^{\prime}\left(\mathrm{m}, \delta_{\mathrm{H}} 3.93\right)$ with $\mathrm{H}-5 \mathrm{a}^{\prime} / \mathrm{H}-7 \mathrm{a}^{\prime}$ and $\mathrm{H}-5 \mathrm{~b}^{\prime} / \mathrm{H}-7 \mathrm{~b}^{\prime}(\mathrm{m}, \delta 1.77$ and 1.69). Once the carbon skeleton was assigned, the correlations observed in the HSQC spectrum provided the identification of the protons attached to each carbon atom (Table 1).

An analogous assignment strategy was applied to the elucidation of the structures of compounds 2, 3, and 4 (Table 1). They showed the same molecular skeleton as compound 1, only differing in the number and/or position of the chlorine atoms bound to the lauryl moiety. Chlorosphaerolactylate B (2) and chlorosphaerolactylate C (3) were isolated together as an oil. They are positional isomers of molecular formula $\mathrm{C}_{15} \mathrm{H}_{27} \mathrm{ClO}_{4}$ with an HRESIMS peak at $\mathrm{m} / \mathrm{z}$ 305.1504/305.1509 $[\mathrm{M}-\mathrm{H}]^{-}$for 2/3. The position of the chlorine atom in each compound was easily determined through the analysis of the 1D and 2D NMR spectroscopic data. For compound 2, six methylene protons appeared overlapped in the chemical shift range of $\delta_{\mathrm{H}} 1.30-1.37$. The correlations originating from the well-resolved signals of the methylene groups at positions $2^{\prime}\left(\mathrm{H}-2^{\prime}, \delta_{\mathrm{H}} 2.37, \mathrm{~m} ; \mathrm{C}-2^{\prime} \delta_{\mathrm{C}}\right.$ $34.9)$ and $12^{\prime}\left(\mathrm{H}-12^{\prime}, \delta_{\mathrm{H}} 3.55, \mathrm{t}, J=6.6 \mathrm{~Hz}\right.$; C-12' $\left.\delta_{\mathrm{C}} 45.7\right)$ provided the connectivity along the fragments $\mathrm{C}-2^{\prime}-\mathrm{C}-5^{\prime}$ and C-12'-C-9', respectively. However, the overlap of signals in the ${ }^{1} \mathrm{H}$ and ${ }^{13} \mathrm{C}$ NMR spectra of the methylene groups $6^{\prime}$ to $8^{\prime}$ prevented their unequivocal assignment. As in compound 1, the distinguishing feature of the chlorine substituent at C- $6^{\prime}$ $\left(\mathrm{H}-6^{\prime}, \delta_{\mathrm{H}} 3.92, \mathrm{~m} ; \mathrm{C}-6^{\prime} \delta_{\mathrm{C}} 64.9\right)$ of compound 3 allowed for the proper assignment of the neighboring methylene groups (Table 1). Compound 4 (chlorosphaerolactylate D) was an oil. The HRESIMS spectrum showed a peak at $\mathrm{m} / z=373.0707$ $[\mathrm{M}-\mathrm{H}]^{-}$consistent with a molecular formula of $\mathrm{C}_{15} \mathrm{H}_{25} \mathrm{Cl}_{3} \mathrm{O}_{4}$. Two of the three chlorine atoms are bound to the terminal carbon of the lauric acid chain, as evidenced by the ${ }^{1} \mathrm{H}\left(\mathrm{H}-12^{\prime}, \delta_{\mathrm{H}} 5.99, \mathrm{t}, J=6.1 \mathrm{~Hz}\right)$ and ${ }^{13} \mathrm{C}\left(\mathrm{C}-12^{\prime} \delta_{\mathrm{C}} 75.0\right)$ chemical shifts. The location of the third chlorine atom at C- $6^{\prime}$ 
$\left(\mathrm{H}-6^{\prime}, \delta_{\mathrm{H}} 3.94, \mathrm{~m} ; \mathrm{C}-6^{\prime} \delta_{\mathrm{C}} 64.8\right)$ was achieved through the observation in the HMBC and COSY NMR spectra of the same set of correlations with neighboring protons as those described above for compound 1 (Figure 2).

The absolute configuration of C-2 was only established for chlorosphaerolactylate A (1), due to the available amounts. Compound 1 was hydrolyzed under acidic conditions, and through chiral-phase HPLC analysis its lactic acid unit was determined as L-lactic acid (Figures S32 and S33), allowing the assignment of the stereocenter at $\mathrm{C}-2$ as $2 S$. Further biosynthetic investigations or synthetic studies will be key to ascertain the configuration at C-6'.

Besides the halogenation found in these new metabolites, they relate closely to commercial lactylates, which are widely used as emulsifying agents in the food and cosmetic industries. In general, lactylates are considered to have nontoxic effects to humans, as well as biodegradable properties, making them very interesting for industrial applications. ${ }^{19-22}$ Given the biotechnological potential of our findings, attention was directed to the minor components of fractions F31-F48 (Figure 1). Hence, further HRESIMS analysis pinpointed the putative existence of other compounds as bislactylates of chlorinated (mono-, di-, and tri-) fatty acids (Table S1, Figures S24-S31).

Compounds 1 and 4 as well as a mixture of compounds 2/3 (51:33 ratio) were tested for antibacterial and antifungal activities using resistant strains derived from clinical isolates: Escherichia coli AR, S. aureus S54F9, ${ }^{18}$ and Candida parapsilosis SMI416. ${ }^{23}$ The compounds showed a weak antibacterial effect $(2.7-6.0 \mathrm{mM})$ against $S$. aureus $\mathrm{S} 54 \mathrm{~F} 9^{18}$ and Candida parapsilosis SMI4 ${ }^{16}$ (Table S2). The same was observed regarding the antibiofilm activity $(0.5-1.1 \mathrm{mM})$ against coagulase-negative $S$. hominis FI31, a clinical isolate collected from an infected prosthesis (Table S2). The reduction of activity observed upon the purification process might be attributed to the effect of the multiple constituents present in the extract and fractions. For instance, other bioactive molecules were identified in the methanolic extract, such as palmitoleic acid and glycerolipids (both showing antibacterial bioactivity). Moreover, the mixture of lactylates and bislactylates of chlorinated fatty acids in the bioactive fractions (Figure 1) might explain the higher antibacterial activity of fractions versus isolated compounds.

Concerning the antibacterial effects of lactylates, most of what is found in the literature arises from patents. For instance, the patent document $\mathrm{WO} 2018222184 \mathrm{Al}^{24}$ refers to antimicrobial compositions, which include sodium isostearyl lactylate, sodium caproyl/lauroyl lactylate, and sodium lauroyl lactylate, for inhibiting microbial growth in personal care products. Likewise, compositions with fatty acid esters as the predominant component were the subject of the US6878757B2 25 patent as an antimicrobial coating for absorbable surgical materials. Furthermore, the patent document US7973006B2 ${ }^{26}$ describes the use of an antibacterial agent (composed of mono- and/or dilactylate esters of octanoic acid, decanoic acid, dodecanoic acid, tetradecanoic acid, palmitic acid, or oleic acid) against Gram-negative bacteria (E. coli, Salmonella sp., Pseudomonas sp., or Campylobacter sp.).

In conclusion, this study describes the structure of four new chlorosphaerolactylates, isolated from the cyanobacterium Sphaerospermopsis sp. LEGE 00249, with weak antibiofilm and antibacterial and antifungal properties. In addition, other putative chlorosphaero(bis)lactylates were detected by LC-MS analysis. These findings taken together add to the knowledge of the fascinating world of cyanobacterial secondary metabolites, namely, to the class of halogenated fatty acid derivatives.

\section{EXPERIMENTAL SECTION}

General Experimental Procedures. Optical rotation was obtained using a P-2000 polarimeter (JASCO). The infrared spectrum was collected on a Nicolet iS5 FTIR spectrometer (ThermoScientific). The 1D and 2D NMR spectrometric data were measured on a Bruker AV600 spectrometer equipped with a $5 \mathrm{~mm}{ }^{1} \mathrm{H},{ }^{13} \mathrm{C},{ }^{15} \mathrm{~N},{ }^{31} \mathrm{P}$ cryoprobe working at a ${ }^{1} \mathrm{H}$ frequency of $600.13 \mathrm{MHz}$ and ${ }^{13} \mathrm{C}$ frequency of $150.9 \mathrm{MHz}$. NMR samples were prepared by dissolving the fraction in $0.5 \mathrm{~mL}$ of $\mathrm{CD}_{3} \mathrm{OD}$ and transferring the solution to a 5 mm NMR tube. The structure elucidation was based on the analysis of a set of $1 \mathrm{D}$ and $2 \mathrm{D}$ NMR spectra including ${ }^{1} \mathrm{H}$, gNOESY $-{ }^{1} \mathrm{H}$ (water suppression), ${ }^{13} \mathrm{C}$, COSY, HSQC-edited, and HMBC. ${ }^{1} \mathrm{H}$ and ${ }^{13} \mathrm{C}$ chemical shifts are expressed in $\delta(\mathrm{ppm})$ referenced to the solvent used $\left(\mathrm{CD}_{3} \mathrm{OD} \delta_{\mathrm{H}} 3.31,4.87\right.$ and $\left.\delta_{\mathrm{C}} 49.0\right)$. Standard Bruker software (TopSpin 3.6) was used for the acquisition and processing of the $1 \mathrm{D}$ and 2D NMR spectra.

Cyanobacterial Strain and Culture Conditions. The cyanobacterium strain Sphaerospermopsis sp. LEGE 00249 was obtained from LEGE-CC ${ }^{27}$ (accession number: KC989701, 16S rRNA gene). The detection of compounds was performed using biomass of cultures grown in laboratory conditions. The strain was cultured up to $50 \mathrm{~L}$ in $\mathrm{Z} 8$ medium ${ }^{28}$ at $25^{\circ} \mathrm{C}$, with constant aeration with a photoperiod of $14 \mathrm{~h} / 10 \mathrm{~h}$ light and dark, respectively, and at a light intensity of 10$30 \mu \mathrm{mol}$ photons $\mathrm{s}^{-1} \mathrm{~m}^{-2}$. At the exponential phase, cells were harvested through centrifugation, then frozen and freeze-dried. In order to obtain a larger amount of biomass from Sphaerospermopsis sp. LEGE 00249 that could allow the isolation and chemical characterization of compounds 1-4, the culture was scaled-up in outdoor conditions. In this context, the strain was cultivated in a modified BG11 medium, ${ }^{29}$ in which nutrients were added according to growth, and gradually adapted to outdoor conditions in particular with regard to light intensity and photoperiod using as culture vessel a $7 \mathrm{~L}$ bubbled tube placed outdoors. A volume containing $15 \mathrm{~g}$ of dry biomass was then transferred to a $40 \mathrm{~L}$ GWP-III photobioreactor ${ }^{30}$ in order to start with an initial biomass concentration of $20 \mathrm{~g} \mathrm{~m}^{-2}$ of reactor illuminated surface. For the first days, the photobioreactor was tilted backward (north facing) to reduce the light intercepted and thus reduce light stress to the culture; then it was tilted $\left(50^{\circ}\right)$ facing south to increase light availability and thus maximize growth and productivity. The culture was kept at a maximum temperature of 28 ${ }^{\circ} \mathrm{C}$ by circulating cold water inside a stainless-steel serpentine placed within the culture chamber, and it was bubbled with air at a flow rate of $0.3 \mathrm{~L} \mathrm{~min}^{-1}$. Pure $\mathrm{CO}_{2}$ was injected when the $\mathrm{pH}$ value exceeded 7.8. The culture was first managed in batch and then in semicontinuous mode with a $30 \%$ daily dilution. In the latter culture regime, the biomass productivity was $7.6 \pm 3.0 \mathrm{~g} \mathrm{~m}^{-2}$ of reactor illuminated surface per day with a solar radiation of $29.6 \pm 0.3 \mathrm{MJ}$ $\mathrm{m}^{-2} \mathrm{day}^{-1}$. The culture was harvested at the steady state by centrifugation, and the biomass frozen and lyophilized prior to use for the following experiments.

Bioactivity-Guided Fractionation and LC-MS Analysis of the Antibiotic Fractions. The procedure is supplied in the Supporting Information.

Consecutive Isolation of Compounds 1-4. The lyophilized biomass obtained from the scaled-up culture $(29.3 \mathrm{~g})$ was sequentially extracted with hexane, EtOH, and $\mathrm{MeOH}$ (Figure S3A). The resultant extracts were joined, yielding $4.4 \mathrm{~g}$, then fractionated by normal-phase VLC (Si gel 60, 0.015-0.040 mm, Merck KGaA) using an increasing polarity grade, with mixtures of $n$-hexane/EtOAc (9:1 to $0: 1)$, EtOAc/MeOH $(7: 3)$, and $\mathrm{MeOH}$, giving a total of nine fractions. The last fraction eluted with $\mathrm{MeOH}$, which revealed the presence of lactylates of chlorinated fatty acids by LC-MS analysis, was further processed through several chromatographic steps using reversed-phase column chromatography (EMD Millipore silica gel 60 $\mathrm{RP}-18$ ) with a gradient of $\mathrm{H}_{2} \mathrm{O} / \mathrm{MeOH}$ (from $1: 1$ to $0: 1$ ). The 
isolation of compounds 1 (5.4 mg), 2 (1.1 mg), 3 (1.1 mg), and 4 ( $1.9 \mathrm{mg}$ ), with purity ranging from $29 \%$ to $84 \%$, was finalized using the retention time in the LC-MS instrument using isocratic conditions, $\mathrm{H}_{2} \mathrm{O} / \mathrm{MeCN}, 2: 3$, both with $0.1 \%$ formic acid (Figures S4-S6).

In order to obtain a larger amount of purer compounds, the lyophilized biomass obtained from the culture scaled up in outdoor conditions (400 g, d.w.) was sequentially extracted with $\mathrm{MeOH}(8 \times$ $4 \mathrm{~L})$. The resultant extract $(134 \mathrm{~g})$ was fractionated by normal-phase VLC (Si gel 60, 0.015-0.040 mm, Merck KGaA) using an increasing polarity grade, with mixtures of $n$-hexane/EtOAc (9:1 to $0: 1$ ), EtOAc/ $\mathrm{MeOH}(7: 3)$, and $\mathrm{MeOH}$, yielding a total of nine fractions. The two last fractions eluted with $\mathrm{EtOAc} / \mathrm{MeOH}(7: 3)$ and $\mathrm{MeOH}$ revealed the presence of lactylates of chlorinated fatty acids (Figure $\mathrm{S} 3 \mathrm{~B}$ ) and were then further processed using reversed-phase column chromatography (EMD Millipore silica gel $60 \mathrm{RP}-18$ ) with gradients of $\mathrm{H}_{2} \mathrm{O} / \mathrm{MeOH}$ (from $1: 1$ to $0: 1$ ) with $0.1 \%$ formic acid. An ionexchange preparative step (Strata SAX SPE tubes, $20 \mathrm{~g} / 60 \mathrm{~mL}$, Phenomenex) was performed before the final purification, carried out with the time-based automatic collector of a Waters Alliance e2695 HPLC instrument coupled with a PDA (photodiode array) detector. The yields obtained for this second batch were as follows: $1(5.4 \mathrm{mg})$, $4(2.9 \mathrm{mg})$, purity $>90 \%$, and mixture $2 / 3(1.8 \mathrm{mg} ; 51: 33$ ratio of both compounds, $84 \%$ pure).

Chlorosphaerolactylate $A$ (2S-[(6,12-dichlorododecanoyl)oxy]propanoic acid) (1): oil; $[\alpha]^{24}{ }_{\mathrm{D}}+33$ (c 0.01, $\left.\mathrm{MeOH}\right)$; IR (KBr) $\nu_{\max } 2937,1736$, and $1725 \mathrm{~cm}^{-1} ;{ }^{1} \mathrm{H}$ and ${ }^{13} \mathrm{C}$ NMR spectroscopic data ( $\mathrm{CD}_{3} \mathrm{OD}$ ), Table 1; HRMS $\mathrm{m} / \mathrm{z} 339.1117[\mathrm{M}-\mathrm{H}]^{-}$(calcd for $\left.\mathrm{C}_{15} \mathrm{H}_{26} \mathrm{Cl}_{2} \mathrm{O}_{4}, 339.1135\right)$.

Chlorosphaerolactylate $B$ ([(12-chlorododecanoyl)oxy]propanoic acid) (2): oil; ${ }^{1} \mathrm{H}$ and ${ }^{13} \mathrm{C}$ NMR spectroscopic data $\left(\mathrm{CD}_{3} \mathrm{OD}\right.$ ), Table 1 ; HRMS $\mathrm{m} / z$ 305.1504 $[\mathrm{M}-\mathrm{H}]^{-}$(calcd for $\left.\mathrm{C}_{15} \mathrm{H}_{27} \mathrm{ClO}_{4}, 305.1525\right)$.

Chlorosphaerolactylate C ([(6-chlorododecanoyl)oxy]propanoic acid) (3). oil; ${ }^{1} \mathrm{H}$ and ${ }^{13} \mathrm{C}$ NMR spectroscopic data $\left(\mathrm{CD}_{3} \mathrm{OD}\right)$, Table 1 ; HRMS $m / z \quad 305.1509[\mathrm{M}-\mathrm{H}]^{-}$(calcd for $\mathrm{C}_{15} \mathrm{H}_{27} \mathrm{ClO}_{4}$, 305.1525).

Chlorosphaerolactylate $D$ ([(6,12,12-trichlorododecanoyl)oxy]propanoic acid) (4): oil; ${ }^{1} \mathrm{H}$ and ${ }^{13} \mathrm{C}$ NMR spectroscopic data $\left(\mathrm{CD}_{3} \mathrm{OD}\right.$ ), Table 1 ; HRMS $\mathrm{m} / z 373.0707[\mathrm{M}-\mathrm{H}]^{-}$(calcd for $\left.\mathrm{C}_{15} \mathrm{H}_{25} \mathrm{Cl}_{3} \mathrm{O}_{4}, 373.0746\right)$.

Acid Hydrolysis of 1 and Chiral-Phase HPLC. Chlorosphaerolactylate $\mathrm{A}(1,1 \mathrm{mg})$ was hydrolyzed in $1 \mathrm{~mL}$ of $0.5 \mathrm{~N} \mathrm{HCl}$ solution in $\mathrm{H}_{2} \mathrm{O} / \mathrm{MeCN}(1: 9)$, at room temperature during $3 \mathrm{~h}$, and afterward the solution was concentrated under vacuum. The hydrolysate and the L-(+)- and D-(-)-lactic acid standards (Santa Cruz Biotechnology) were dissolved in $\mathrm{H}_{2} \mathrm{O}(0.5 \mathrm{mg} / \mathrm{mL})$ and eluted through a chiralphase column, Chirex 3126 (D)-penicillamine $(50 \times 4.6 \mathrm{~mm}$, Phenomenex), using a $2 \mathrm{mM} \mathrm{CuSO}{ }_{4} / \mathrm{H}_{2} \mathrm{O}$ solution, at a flow rate of $1 \mathrm{~mL} / \mathrm{min}$. The chromatograms at $245 \mathrm{~nm}$ of the hydrolysate were compared with the standards L- and D-lactic acid (Figures S32 and S33).

Bacterial Strains and Culture Conditions. E. coli clinical isolate (AR-collected from urine at the Hospital Clinic of Barcelona), $S$. aureus spa type t1333 (S54F9), ${ }^{18}$ and C. parapsilosis clinical isolate from a bloodstream infection (SMI416) ${ }^{23}$ were employed for antibacterial and antifungal activities. E. coli, S. aureus, and C. parapsilosis were resuscitated on $\mathrm{MH}$ agar (Mueller-Hinton Agar, Oxoid) at $37{ }^{\circ} \mathrm{C}$ from $25 \%$ glycerol (v/v) stocks kept at $-20{ }^{\circ} \mathrm{C}$ and maintained thereafter at $4{ }^{\circ} \mathrm{C}$. Coagulase-negative $S$. hominis FI31 is a clinical isolated collected from an infected prosthesis at the Hospital Clinic of Barcelona. Bacterial culture media were purchased from ThermoScientific. All other solutions and media were made with ultrapure deionized water and were sterilized by autoclaving at $121^{\circ} \mathrm{C}$ for $15 \mathrm{~min}$.

Antibiotic and Antibiofilm Assays. See Supporting Information for details.

\section{ASSOCIATED CONTENT}

\section{Supporting Information}

The Supporting Information is available free of charge at https://pubs.acs.org/doi/10.1021/acs.jnatprod.0c00072.

Additional information (PDF)

\section{AUTHOR INFORMATION}

\section{Corresponding Authors}

Mariana A. Reis - Interdisciplinary Centre of Marine and Environmental Research (CIIMAR/CIMAR), Terminal de Cruzeiros do Porto de Leixoes, University of Porto, 4450-208 Matosinhos, Portugal; 이이이.org/0000-0001-8737-2138; Email: mreis@ciimar.up.pt

Fernando López Ortiz - Area de Química Orgánica, Research Centre CIAIMBITAL, Universidad de Almeria, 04120, Spain; ○ orcid.org/0000-0003-1786-0157; Email: flortiz@ual.es

\section{Authors}

Ignacio Gutiérrez-del-Río - Departamento de Biología Funcional), IUOPA (Instituto Universitario de Oncologia del Principado de Asturias), IISPA (Instituto de Investigación Sanitaria del Principado de Asturias), Research Unit "Biotechnology in Nutraceuticals and Bioactive CompoundsBIONUC", Universidad de Oviedo ('Area de Microbiologia, 3 Oviedo, Spain

Nelly Brugerolle de Fraissinette - Interdisciplinary Centre of Marine and Environmental Research (CIIMAR/CIMAR), Terminal de Cruzeiros do Porto de Leixões, University of Porto, 4450-208 Matosinhos, Portugal

Raquel Castelo-Branco - Interdisciplinary Centre of Marine and Environmental Research (CIIMAR/CIMAR), Terminal de Cruzeiros do Porto de Leixóes, University of Porto, 4450-208 Matosinhos, Portugal

Flavio Oliveira - Interdisciplinary Centre of Marine and Environmental Research (CIIMAR/CIMAR), Terminal de Cruzeiros do Porto de Leixões, University of Porto, 4450-208 Matosinhos, Portugal

João Morais - Interdisciplinary Centre of Marine and Environmental Research (CIIMAR/CIMAR), Terminal de Cruzeiros do Porto de Leixoes, University of Porto, 4450-208 Matosinhos, Portugal

Saúl Redondo-Blanco - Departamento de Biología Funcional), IUOPA (Instituto Universitario de Oncologia del Principado de Asturias), IISPA (Instituto de Investigación Sanitaria del Principado de Asturias), Research Unit "Biotechnology in Nutraceuticals and Bioactive Compounds-BIONUC", Universidad de Oviedo ('Area de Microbiología, 3 Oviedo, Spain Claudio J. Villar - Departamento de Biologia Funcional), IUOPA (Instituto Universitario de Oncologia del Principado de Asturias), IISPA (Instituto de Investigación Sanitaria del Principado de Asturias), Research Unit "Biotechnology in Nutraceuticals and Bioactive Compounds-BIONUC", Universidad de Oviedo (Área de Microbiologia, 3 Oviedo, Spain

María José Iglesias - Área de Quimica Orgánica, Research Centre CIAIMBITAL, Universidad de Almeria, 04120, Spain

Raquel Soengas - Área de Quimica Orgánica, Research Centre CIAIMBITAL, Universidad de Almeria, 04120, Spain

Virginio Cepas - ISGlobal, Hospital Clinic, Universitat de Barcelona, 08036 Barcelona, Spain

Yuly López Cubillos - ISGlobal, Hospital Clinic, Universitat de Barcelona, 08036 Barcelona, Spain 
Giacomo Sampietro - Fotosintetica \& Microbiologica S.r.l., 50132 Firenze, Italy

Liliana Rodolfi - Fotosintetica \& Microbiologica S.r.l., 50132 Firenze, Italy

Felipe Lombó - Departamento de Biología Funcional), IUOPA (Instituto Universitario de Oncología del Principado de Asturias), IISPA (Instituto de Investigación Sanitaria del Principado de Asturias), Research Unit "Biotechnology in Nutraceuticals and Bioactive Compounds-BIONUC", Universidad de Oviedo (Área de Microbiología, 3 Oviedo, Spain

Sara M. Soto González - ISGlobal, Hospital Clinic, Universitat de Barcelona, 08036 Barcelona, Spain

Vitor Vasconcelos - Interdisciplinary Centre of Marine and Environmental Research (CIIMAR/CIMAR), Terminal de Cruzeiros do Porto de Leixoes, University of Porto, 4450-208 Matosinhos, Portugal; Faculdade de Cîncias, Universidade do Porto, 4169-007 Porto, Portugal

Complete contact information is available at:

https://pubs.acs.org/10.1021/acs.jnatprod.0c00072

\section{Author Contributions}

\#I.G.R., N.B.F., and R.C.B. contributed equally to this work, sharing the first coauthorship.

Notes

The authors declare the following competing financial interest(s): The contents of the manuscript were the subject of a Portuguese provisional patent application (No: 115761, Halogenated compounds and uses thereof, August 2019).

\section{ACKNOWLEDGMENTS}

This work was funded by the European Commission under the H2020 program, NoMorFilm Project (Grant Agreement 634588). CIIMAR was additionally supported by the FCT strategic funds UIDB/04423/2020 and UIDP/04423/2020. R.C.B. acknowledges financial support from Fundação para a Ciência e a Tecnologia (FCT) fellowship SFRH/BD/136367/ 2018. University of Oviedo also thanks Programa de Ayudas a Grupos de Investigación del Principado de Asturias (IDI/ 2018/000120) and Programa Severo Ochoa de Ayudas Predoctorales para la Investigación y Docencia from Principado de Asturias (Grant BP16023 to I.G.R.). HRESIMS experiments were conducted at the mass spectrometry unit of the University of Oviedo (Servicios Cientifico-Técnicos). ISGlobal is a CERCA center from the Generalitat of Catalunya and a Severo Ochoa Center (Spanish Ministry of Science, Innovations and Universities) supported by Planes Nacionales de I+D+i 2008-2011/2013-2016 and Instituto de Salud Carlos III, Subdirección General de Redes y Centros de Investigación Cooperativa, Ministerio de Economía y Competitividad, Spanish Network for Research in Infectious Diseases (REIPI RD12/0015/0013 and REIPI RD16/0016/0010) cofinanced by the European Development Regional Fund "A Way to Achieve Europe" and operative program Intelligent Growth 2014-2020. The authors acknowledge the support and the use of resources of EMBRC-ERIC, specifically of the Portuguese infrastructure node of the European Marine Biological Resource Centre (EMBRC-PT) CIIMAR-PINFRA/22121/ 2016-ALG-01-0145-FEDER-022121, financed by the European Regional Development Fund (ERDF) through COMPETE2020-Operational Programme for Competitiveness and Internationalisation (POCI) and national funds through FCT/ MCTES.

\section{REFERENCES}

(1) Dittmann, E.; Gugger, M.; Sivonen, K.; Fewer, D. P. Trends Microbiol. 2015, 23 (10), 642-652.

(2) Newman, D. J.; Cragg, G. M. J. Nat. Prod. 2016, 79 (3), 629661.

(3) Demay, J.; Bernard, C.; Reinhardt, A.; Marie, B. Mar. Drugs 2019, 17 (6), 1-49.

(4) Dembitsky, V. M.; Srebnik, M. Prog. Lipid Res. 2002, 41 (4), 315-367.

(5) Gribble, G. W. ARKIVOC 2019, 2018 (1), 372-410.

(6) Atashgahi, S.; Häggblom, M. M.; Smidt, H. Environ. Microbiol. 2018, 20 (3), 934-948.

(7) Neumann, C. S.; Fujimori, D. G.; Walsh, C. T. Chem. Biol. 2008, 15 (2), 99-109.

(8) Kan, Y.; Sakamoto, B.; Fujita, T.; Nagai, H. J. Nat. Prod. 2000, 63

(12), 1599-1602.

(9) Edwards, D. J.; Marquez, B. L.; Nogle, L. M.; Mcphail, K.; Goeger, D. E.; Roberts, M. A.; Gerwick, W. H. Chem. Biol. 2004, 11 (6), 817-33.

(10) Jiménez, J. I.; Vansach, T.; Yoshida, W. Y.; Sakamoto, B.; Pörzgen, P.; Horgen, F. D. J. Nat. Prod. 2009, 72 (9), 1573-1578.

(11) Lopez, J. A. V.; Petitbois, J. G.; Vairappan, C. S.; Umezawa, T.; Matsuda, F.; Okino, T. Org. Lett. 2017, 19 (16), 4231-4234.

(12) Moore, R. E.; Bornemann, V.; Niemczura, W. P.; Gregson, J. M.; Chen, J. L.; Norton, T. R.; Patterson, G. M. L.; Helms, G. L. J. Am. Chem. Soc. 1989, 111 (16), 6128-6132.

(13) Luesch, H.; Yoshida, W. Y.; Moore, R. E.; Paul, V. J.; Mooberry, S. L. J. Nat. Prod. 2000, 63 (5), 611-615.

(14) Mercer, E. I.; Davies, C. L. Phytochemistry 1975, 14 (7), 15451548.

(15) Moosmann, P.; Ueoka, R.; Gugger, M.; Piel, J. Org. Lett. 2018, 20 (17), 5238-5241.

(16) Cepas, V.; López, Y.; Gabasa, Y.; Martins, C. B.; Ferreira, J. D.; Correia, M. J.; Santos, L. M. A.; Oliveira, F.; Ramos, V.; Reis, M.; Castelo-Branco, R.; Morais, J.; Vasconcelos, V.; Probert, I.; Guilloud, E.; Mehiri, M.; Soto, S. M. Antibiotics 2019, 8 (2), 1-12.

(17) Martins, J.; Leikoski, N.; Wahlsten, M.; Azevedo, J.; Antunes, J.; Jokela, J.; Sivonen, K.; Vasconcelos, V.; Fewer, D. P.; Leão, P. N. Sci. Rep. 2018, 8 (1), 1-9.

(18) Aalbæk, B.; Jensen, L. K.; Jensen, H. E.; Olsen, J. E.; Christensen, H. Genome Announc. 2015, 3 (5), 9-10.

(19) Boutte, T.; Skogerson, L. Emuls. food Technol. 2004, 206-225.

(20) Wang, F. C.; Marangoni, A. G. J. Colloid Interface Sci. 2016, 483, 394-403.

(21) Shah, R.; Kolanos, R.; DiNovi, M. J.; Mattia, A.; Kaneko, K. J. Food Addit. Contam., Part A 2017, 34 (6), 905-917.

(22) Draelos, Z. D.; Donald, A. J. Drugs Dermatol. 2018, 17 (6), 671-676.

(23) Pannanusorn, S.; Ramírez-Zavala, B.; Lünsdorf, H.; Agerberth, B.; Morschhäuser, J.; Römling, U. Eukaryotic Cell 2014, 13 (4), 438451.

(24) Jeffery, R.; Paige, N.; Corey, T.; Luke, D. WO2018222184A1, 2018.

(25) Roby, M. US6878757B2, 2005.

(26) Ramirez, M.; Kremer, D. R. US7973006B2, 2011.

(27) Ramos, V.; Morais, J.; Castelo-Branco, R.; Pinheiro, Â.; Martins, J.; Regueiras, A.; Pereira, A. L.; Lopes, V. R.; Frazão, B.; Gomes, D.; Moreira, C.; Costa, M. S.; Brûle, S.; Faustino, S.; Martins, R.; Saker, M.; Osswald, J.; Leão, P. N.; Vasconcelos, V. M. J. Appl. Phycol. 2018, 30, 1-15.

(28) Kotai, J. Nor. Inst. Water Res. 1972, 11 (69), 5.

(29) Rippka, R. Methods Enzymol. 1988, 167, 3-27.

(30) Rodolfi, L.; Biondi, N.; Guccione, A.; Bassi, N.; D’Ottavio, M.; Arganaraz, G.; Tredici, M. R. Biotechnol. Bioeng. 2017, 114 (10), 2204-2210. 